\title{
USING EYE-TRACKING TO INVESTIGATE TOPICS \\ IN L2 ACQUISITION AND \\ L2 PROCESSING
}

\section{Leah Roberts}

University of York

\author{
Anna Siyanova-Chanturia \\ Victoria University of Wellington
}

\begin{abstract}
Second language (L2) researchers are becoming more interested in both L2 learners' knowledge of the target language and how that knowledge is put to use during real-time language processing. Researchers are therefore beginning to see the importance of combining traditional $L 2$ research methods with those that capture the moment-by-moment interpretation of the target language, such as eye-tracking. The major benefit of the eye-tracking method is that it can tap into real-time (or online) comprehension processes during the uninterrupted processing of the input, and thus, the data can be compared to those elicited by other, more metalinguistic tasks to offer a broader picture of language acquisition and processing. In this article, we present an overview of the eye-tracking technique and illustrate the method with L2 studies that show how eye-tracking data can be used to (a) investigate language-related topics and (b) inform key debates in the fields of $L 2$ acquisition and $\mathrm{L} 2$ processing.
\end{abstract}

We would like to thank two anonymous reviewers for their helpful comments on previous versions of this article.

Correspondence concerning this article should be addressed to Anna SiyanovaChanturia, School of Linguistics and Applied Language Studies, Victoria University of Wellington, Wellington, New Zealand, 6140. E-mail: anna.siyanova@vuw.ac.nz 
In the last few years, more second language (L2) researchers are combining tasks that measure real-time processing with established methods such as judgment and questionnaire tasks to more fully assess learners' knowledge of the target language. Although there are a number of online techniques that can be used (see Roberts, 2012b, for an overview), the eye-movement method is a particularly useful tool for L2 acquisition researchers because it allows for the study of moment-by-moment processing decisions during natural, uninterrupted comprehension, and critically, without the need to rely on participants' strategic or metalinguistic responses (Rayner, 1998, 2009). This is important given that recent meta-analyses of data-particularly judgment tasks and questionnaires-from the L2 processing literature suggest that it may be task conditions that specifically force participants to attend to the (grammatical) details of the input where learners' processing is most nativelike (Indefrey, 2006) or where individual differences in factors such as proficiency, cognitive capacity, and processing speed may come into play (Roberts, 2012a).

The eye-movement method, also known as eye-tracking (a more colloquial but rather common term, which we will use in the present article) can be divided into methods that (a) tap into reading processes and (b) track the eyes as they move over a visual scene during the processing of auditory input (i.e., the visual-world paradigm). In the visual-world paradigm, research has shown that within $200 \mathrm{~ms}$ of hearing a word in the input, the eyes will move to an image of the word that appears on the screen (Altmann, 2011). This method has therefore been successfully used in both monolingual and L2 processing research to investigate word recognition (e.g., Marian \& Spivey, 2003) and anaphor resolution (e.g., the real-time interpretation of subject pronouns in auditory discourse, see Ellert, 2011; Ellert, Järvikivi, \& Roberts, in press; Wilson, 2009). However, the reading technique has been used in the majority of L2 eye-tracking studies, and so it is on this technique that we focus in the current article. We first describe the technique in some detail and outline the processes that psychologists and psycholinguists assume that the method accesses. We then summarize a selection of studies that illustrate how eye-tracking during reading has been used to investigate key topics in the fields of $\mathrm{L} 2$ acquisition and $\mathrm{L} 2$ processing. We provide an overview of studies in which researchers have used eyetracking to examine questions surrounding the nature of the bilingual mental lexicon ${ }^{1}$ and then move on to studies in which L2 learners' grammatical knowledge and real-time processing of the target language have been investigated. In this frame, researchers often seek to establish how nativelike L2 learners' performance is, and, as such, the studies focus on (a) learners' sensitivity to ambiguities and ungrammaticalities and (b) how (structural) dependencies are established during online comprehension. 


\section{WHAT EYE-TRACKING MEASURES AND WHAT PROCESSES ARE ASSUMED TO BE ACCESSED}

Reading is thought to be the most complex cognitive activity humans engage in on a daily basis (Rayner \& Pollatsek, 1989). Numerous studies have investigated the processes involved in the reading of ambiguities, polysemy, figurative speech, garden paths, expectancies, ungrammaticalities, and so on in a first language (L1) and a L2. To this aim, various methodologies have been used over the last few decades. One that has proved to be particularly suitable for disentangling different processes and stages of reading is eye-tracking.

During reading, rapid eye movements are made from one fixation point to another. These movements are called saccades. Because saccades are so fast, it is believed that no new information input occurs during saccadic movements (Liversedge, Paterson, \& Pickering, 1998; Rayner, $1998,2009)$. In between saccades, the eyes remain stationary for just about as long as needed to recognize a word (Rayner, 1998, 2009). Such stops are called fixations. Analyses of fixations-including their number and durations - offer invaluable information with respect to the features of the text being processed.

In skilled readers of alphabetic languages, mean fixation durations on an individual word are about $200-250 \mathrm{~ms}$, and the mean saccade length is around 7-9 letter spaces (Rayner, 1998, 2009). Whereas most words are fixated at least once, some words, especially shorter and more frequent ones, are skipped altogether. Carpenter and Just (1983) report that content words are fixated $85 \%$ of the time, as opposed to function words, which receive fixations only $35 \%$ of the time. This is not surprising because function words are among the most frequent words in language and are also the shortest. Similarly, shorter and more frequent content words have been shown to be skipped more often than longer and less frequent ones, and, additionally, they receive shorter and fewer fixations (Altarriba, Kroll, Scholl, \& Rayner, 1996; Brysbaert, Drieghe, \& Vitu, 2005; Brysbaert \& Vitu, 1998; Inhoff \& Rayner, 1986; Rayner \& Duffy, 1986). Contextual constraints have also been shown to affect the amount of skipping and fixation durations (Balota, Pollatsek, \& Rayner, 1985; Ehrlich \& Rayner, 1981; Rayner \& Well, 1996). These studies found that words that are highly predictable-given the preceding sentential or textual context-are skipped more frequently and are characterized by shorter fixation durations than words that are less constrained by the preceding context.

Although the nature of reading is progressive, it is not just about moving forward from left to right (in left-to-right languages like English). Around $10-15 \%$ of all saccadic movements are, in fact, regressionsthat is, eye movements from right to left (Rayner, 1998, 2009). Regressions 
can be short (i.e., a few letters long within a given word), which suggests processing difficulties specific to the word; they can also be longer movements made to earlier words in a sentence, or, indeed, to previous sentences in a larger text. Such long regressions imply processing difficulties and comprehension failures with respect to a larger sentential context. Ambiguous and polysemous words, problems with context integration, and garden path effects are often characterized by longer regressions. General text difficulty also contributes to a larger number of regressions being made (Rayner \& Pollatsek, 1989). Although most regressions are the result of a range of comprehension failures, some regressions are very short saccades due to oculomotor errors (Rayner, 1998). It is noteworthy that the probability of regressive eye movements increases when they follow longerrather than shorter-forward saccades (Vitu, McConkie, \& Zola, 1998). This implies that long saccades are less accurate and may lead to wrongly placed forward fixations and subsequent rereading (Rayner, 1998).

An interesting effect implicated in the processing of single words, especially low-frequency ones, is spillover. The time spent on a lowfrequency word can spill over onto the following word and thus inflate this word's initial reading times (Kennison \& Clifton, 1995; Rayner \& Duffy, 1986; Rayner, Sereno, Morris, Schmauder, \& Clifton, 1989; White, 2008). It is, therefore, common practice in eye-tracking reading research to analyze fixation durations made not only on a given region of interest but also on the word(s) immediately following it.

One of the important questions in reading research regards the size of the perceptual span-namely, the amount of information a reader can extract during a given fixation. A number of researchers have proposed that the size of the perceptual span in alphabetical languages like English is 3-4 characters to the left of a given fixation and 14-15 characters to the right of this fixation (McConkie \& Rayner, 1975; Pollatsek, Rayner, \& Balota, 1986; Rayner \& Bertera, 1979; Rayner, Well, \& Pollatsek, 1980). However, as text difficulty increases, the perceptual span decreases (Henderson \& Ferreira, 1990). The relatively large perceptual span to the right of a given fixation suggests that some information about the upcoming word becomes available in the parafovea-namely, the three degrees of the visual field that extend to the left and right of the center of vision (Rayner, 1998). Indeed, it has been shown that readers are able to extract some information about the word to the right of the current fixation (Balota et al., 1985; Henderson \& Ferreira, 1990; Inhoff, 1989; Rayner, 1975). In the case of shorter words, Rayner $(1998,2009)$ argues that the information available in the parafovea allows the reader to identify the word with some degree of certainty and to decide if it can be skipped. In the case of longer 
words, however, the partial-word information in the parafovea is unlikely to allow their full identification, but it may still facilitate their processing (i.e., a phenomenon known as parafoveal preview benefit). Frequent words are also more likely to be processed parafoveally (and therefore skipped) than less frequent ones (Inhoff \& Rayner, 1986).

Eye-movement recordings can thus tell us exactly what has been fixated or refixated (and for how long), or what has been skipped altogether. Such series of fixations, saccades, regressions, and skippings are undoubtedly one of the richest accounts of real-time human language processing (see Frenck-Mestre, 2005). One of the advantages of this methodology is that, unlike self-paced reading (SPR) experiments, no secondary task is necessary: Readers are engaged in the task of normal reading and can proceed entirely at their natural pace. Eye-tracking is therefore believed to permit reading that is as close to natural as possible in an experimental setting (e.g., Duyck, Van Assche, Drieghe, \& Hartsuiker, 2007). It allows researchers to tap into comprehension processes as they occur in real time during the uninterrupted processing of the input, without participants having to make a strategic or metalinguistic response.

Another, and perhaps the greatest, advantage of the eye-tracking paradigm is the possibility to tease apart early and late processes of online reading. This means that both early and late effects of the experimental manipulation can be detected and examined separately. For example, it is possible to look at fixations made during first-time reading and then subsequent fixations that may have been the result of a particular processing difficulty. It is generally assumed that early measures (e.g., first fixation duration and gaze duration) are sensitive to early processes in the comprehension of a text, such as lexical access and early integration of information. Late measures (e.g., total reading time), in contrast, are believed to be sensitive to later processes associated with comprehension of a text, such as information reanalysis, discourse integration, and recovery from processing difficulties (Paterson, Liversedge, \& Underwood, 1999; Rayner et al., 1989).

Because early and late measures are thought to tap into different processes, it is imperative to analyze both. As Rayner (1998) argues, any single measure is "a pale reflection of the reality of cognitive processing" and is of limited value in measuring online processing (p. 377). For example, in an idiom comprehension study, Siyanova-Chanturia, Conklin, and Schmitt (2011) demonstrated that where the early measure failed to detect any processing differences between the conditions, later ones did reveal differences. The authors proposed that during the reading of longer strings of language, such as idioms (as opposed to single words), early measures may not be suitable for detecting potential 
differences between the conditions. Previous research with single words also suggests that length manipulations may affect early eyetracking measures differently from later ones (Hyönä, 1993; Rayner \& Well, 1996).

It has, therefore, been proposed that to obtain a more complete picture of the cognitive processes involved in reading, a variety of measures-both early and late-need to be analyzed. According to Rayner $(1998,2009)$, the choice of eye-movement measures depends on, among other things, the size of the unit of analysis-that is, a single word or an area larger than a word (e.g., a phrasal unit; see SiyanovaChanturia, Conklin, \& Schmitt, 2011; Siyanova-Chanturia, Conklin, \& van Heuven, 2011). With this in mind, we list some of the commonly used eye-tracking measures. Figure 1 reflects a hypothetical sequence of fixations and references the measures described below. The first two measures listed are considered to be early measures (although gaze duration is sometimes referred to as a midmeasure [McDonald \& Shillcock, 2003]). The next four are late measures. ${ }^{2}$ The last measure, fixation count, although not a measure of processing time, is often reported in eye-tracking studies.
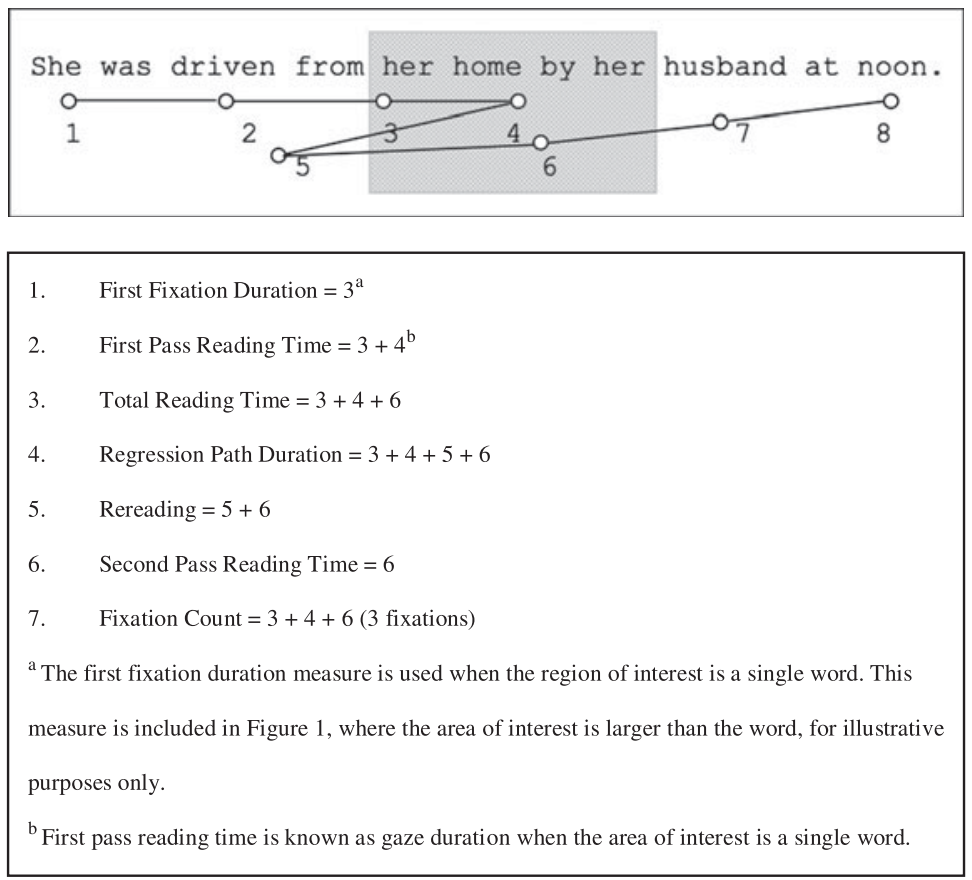

Figure 1. Hypothetical eye-movement record. The shaded area represents the region of interest. 
1. First fixation duration refers to the duration of the first fixation within the area of interest irrespective of whether it is the only fixation or the first of multiple fixations within this region (represented by 3 in Figure 1). First fixation duration is the most commonly used index in word-recognition research. This measure is taken to be the earliest point when one may expect to observe an effect due to the experimental manipulation, such as lexical frequency (Liversedge et al., 1998). It is important to note that first fixation duration is a useful measure only when the region of interest is a word; it is not a suitable (or informative) measure for a region that is larger than a single word because as regions get larger, the probability of further fixations on these regions increases.

2. Gaze duration refers to the sum of all fixation durations made within a region of interest until the gaze exited either to the left or to the right. This measure tells us how long the reader fixated the target the first time it was encountered. This measure has been found to be sensitive to semantic and syntactic anomalies (Rayner, Warren, Juhasz, \& Liversedge, 2004). Rayner (1998) points out that first fixation duration and gaze duration often produce comparable results. However, it is noteworthy that this only holds true for a region of interest made up of a single word, which is likely to receive only one fixation. When a region of interest is larger than a single word-for example, an idiom or a collocation (Siyanova-Chanturia, Conklin, \& Schmitt, 2011; SiyanovaChanturia, Conklin, \& van Heuven, 2011)—then the total first pass reading time on that region, which is the initial reading consisting of all forward fixations (represented by $3+4$ in Figure 1), should be used as the primary eye-movement measure (Rayner, 1998).

3. Total reading time refers to the sum of all fixation durations made within a region of interest. This measure includes all fixations that landed on the target and indicates how much time the participant spent reading the target (represented by $3+4+6$ in Figure 1). Liversedge et al. (1998) propose that the total reading time measure is a mixture of initial processing time as well as the time that may have been spent recovering from processing difficulties. They further argue that if an effect is observed for this measure-but not for an earlier one, such as gaze duration or first pass reading time-then this may be indicative of the manipulation having a late effect on processing. Total reading time is reported when the region of interest is a single word or a longer phrase.

4. Regression path duration (also known as go-past time) is the sum of all fixation durations, which starts with the first fixation within a region of interest up to-but excluding - the first fixation to the right of this region. This measure gives the durations of all fixations that were made on the target as well as all later regressions to the left of the target (represented by $3+4+5+6$ in Figure 1). This measure is the most inclusive one and has been shown to be sensitive to manipulations of congruity (Camblin, Gordon, \& Swaab, 2007). Unlike first fixation duration and gaze duration (or first pass reading time), it is also thought to be an indicator of higher order reading processes-for example, semantic and syntactic integration (De Groot, 2011). Similar to the total reading time measure, regression path duration can be used when the region of interest is a word or a larger unit. 
5. Rereading is calculated as regression path duration for the region of interest minus gaze duration or first pass reading time for this region. Rereading time gives an indication of the time the participant spent rereading the text after having encountered a problem (represented by $5+6$ in Figure 1).

6. Second pass reading time refers to the sum of all fixation durations made within a region of interest after the region was exited and reentered for the first time (represented by 6 in Figure 1). According to Rayner (1998), when analyzing larger units (e.g., phrases), it is important to distinguish between first pass and second pass reading time for the region.

7. Fixation count captures the number of all fixations made within a given region of interest, a single word, or a longer stretch of language. It is worth noting that fixation count is not a measure of processing time; rather, it indicates how many times the target was fixated (represented by $3+4+6$ in Figure 1).

Given that eye-tracking stands apart from other techniques in its ability to capture regressions, the probability of making a first pass regression from a target word or region is another commonly used eye-movement measure (albeit not a measure of processing time). First pass regression probability is the percentage of leftward eye movements from a currently fixated word or region to a preceding one (Van Gompel \& Pickering, 2001; Vasishth \& Drenhaus, 2011). This measure has been argued to index increased processing load (Vasishth \& Drenhaus, 2011).

In addition to looking at early and late time-based measures as well as fixation count and first pass regression probability (i.e., non-time-based measures), Liversedge et al. (1998) suggested summing up fixation durations that are spatially and temporally contiguous in the text. Spatially contiguous fixations are those that "neighbour each other in a specified region of space" (p. 55), such as total reading time, whereas temporally contiguous fixations are those fixations that "occur in a sequence over a specified period of time" (p. 55), such as regression path duration. Liversedge et al. argued that both approaches are needed to fully understand the influence of a linguistic variable on readers' processing of a text; in particular, those effects attributed to processing recovery. Reporting both spatially and temporally contiguous measures minimizes the possibility that an effect may not be detected. It is important to note, however, that in the absence of regressions or word skippings, spatially and temporally contiguous measures will coincide.

Eye-tracking thus allows researchers to obtain a detailed, multilayered account of the processes involved in normal reading by separating earlier and later processing stages as well as by examining spatially and temporally contiguous fixations. This is unlike other reading techniques, such as SPR, which can only provide a researcher with one measurenamely, total reading time of a particular segment (Frenck-Mestre, 2005). Additionally, whereas during an eye-tracking experiment readers can proceed entirely at their normal speed, reading rate in SPR experiments is only about half as fast as natural reading (Rayner, 1998). 
Another disadvantage of SPR is that it prevents, or interferes with, readers' creation of a natural prosodic contour for the sentence, which is claimed to be particularly important in syntactic ambiguity resolution (Fodor, 2002).

In sum, eye-movement data are believed to reflect the momentto-moment cognitive processes during natural reading (Just \& Carpenter, 1980; Rayner, 1998, 2009; Rayner et al., 1989), and the different eye-tracking measures are able to provide a multidimensional or multifaceted picture of reading. All of these factors render this methodology an invaluable tool in the investigation of online language comprehension in the L1 and L2. In the next section, we provide a brief overview of some studies in which this technique has been used successfully to address questions that arise from current debates in the L2 acquisition and L2 sentenceprocessing fields.

\section{EYE-TRACKING AS A MEANS TO INVESTIGATE L2 ACQUISITION AND L2 PROCESSING}

\section{Lexical Processing}

A critical question in the study of L2 processing is how words from the two languages of a L2 speaker are represented and processed in the mental lexicon. One possibility is that lexical representations from each language are stored and accessed separately (i.e., lexical processing is language selective). However, most recent research converges on the idea that words from both languages are integrated into one lexicon; that is, the bilingual mental lexicon appears to be language nonselective. Much of the evidence for this nonselectivity comes from studies that use cognates and interlingual homographs (i.e., words that have the same orthographic form but differ in meaning across languages such as coin: French "corner," English "coin"). Such studies have shown that when a word is processed in one language, words from the other language become activated (e.g., Lemhöfer \& Dijkstra, 2004; Schwartz, Kroll, \& Diaz, 2007), even when reading in one's L1 (e.g., Van Assche, Duyck, Hartsuiker, \& Diependaele, 2009). A major finding in the work on language nonselectivity is the cognate facilitation effect; that is, cognates are recognized and produced faster than noncognates (e.g., Costa, Caramazza, \& Sebastián-Gallés, 2000; Lemhöfer \& Dijkstra, 2004; Lemhöfer, Dijkstra, \& Michel, 2004; Schwartz et al., 2007; Van Hell \& Dijkstra, 2002). This is assumed to be the case because, when a word is presented, activation at all levels (i.e., orthographic, phonological, and semantic) occurs and spreads across representations of both languages, and this interaction between languages facilitates processing. Studies using interlingual homographs have also found cross-language effects, but 
unlike cognates, these items cause processing slowdowns (i.e., interference). The interference effect is assumed to be caused by the fact that the lexical activation of the two forms (i.e., target and nontarget language) do not converge on the same meaning, which interferes with the comprehension process.

Cognate facilitation and interlingual homograph interference effects have been observed in many studies using various methods (e.g., probe recognition and lexical decision tasks) with words presented in isolation, and the question arises as to whether or not such effects can be observed when words appear in sentence contexts, which, as it has been well established, influences monolingual lexical access and processing (e.g., Duffy, Kambe, \& Rayner, 2001). Eye-tracking has been used with good effect to investigate the question of the potential influence of different types of sentence contexts on bilingual lexical processing because it allows for researchers to examine the time course of processing, and in particular, the points at which cross-language activation effects do or do not come into play. The findings of an early study on the processing of translation equivalents by Altarriba et al. (1996) suggested that sentence context should indeed influence lexical processing in bilinguals. Translation equivalents were set in L2 sentences (e.g., He wanted to deposit all of his dinero [money] at the credit union). Semantically, the critical (switched language) word was predictable from the sentence context (i.e., high-constraining context). The participants' first fixation and gaze durations were slower in comparison to (a) the same words in low-constraining sentence contexts and (b) translations of the same words in unilingual contexts (e.g., money). Furthermore, the learners were significantly more likely to skip an English target word than a Spanish word in an English sentence. Thus, a high-constraining sentence context was seen to reduce the observed cognate facilitation effect in all measures. In sum, these findings suggest that the activation of nontarget lexical representations is immediately inhibited by sentence context. In other words, lexical access can be constrained by language.

Using cognates rather than translation equivalents, Duyck et al.'s (2007) eye-tracking study presented their participants with single-language materials rather than the mixed-language ones used in the Altarriba et al. (1996) study. Dutch-English bilinguals read sentences with critical words, which were either identical (e.g., ring) or nonidentical (e.g., cat vs. kat) cognates. Unlike in the Altarriba et al. study, the critical words were all embedded in low-constraining sentences (e.g., Lucia returned with a beautiful cat [cognate] - bag [control] from the market). The authors report a cognate facilitation effect in all reading time measures (i.e., first fixation, regression path times, and gaze duration), but interestingly, this was only the case for identical cognates. This suggests that in all stages of lexical processing-including readers' first fixations, which are thought to reflect initial lexical access-interlingual interactions 
between L1 and L2 lexical representations occur even when only one language is required for comprehension. However, this may only be the case when there is maximum lexical overlap between the items, which is in line with the results of visual word recognition studies that have focused on single-word processing (e.g., Dijkstra, Grainger, \& Van Heuven, 1999). Furthermore, given the fact that the words were presented in unilingual sentences, the results suggest that the top-down cue of language may not be enough to completely inhibit activation of the bilingual's other language, at least in low-constraining sentence contexts.

As regards the influence of lower versus higher semantic constraints, many studies that employ translation and word recognition tasks have found that crosslinguistic activation effects are eliminated when words are presented in highly constrained sentence contexts, at least with very proficient learners (e.g., Van Hell \& De Groot, 2008). Eye-tracking during reading has been found to offer a more detailed picture of this process. However, Libben and Titone (2009) examined French-English bilinguals' reading of English sentences containing interlingual homographs (e.g., chat: French "cat," English "chat") and cognates (e.g., divorce) and found the predicted interference effects for interlingual homographs as well as processing advantage effects for the cognates in all fixation time measures for the low-constraining sentences (e.g., Since they really liked each other, they had an extended chat that lasted all night.). As found in earlier studies, this effect was modulated by sentence context, but it was not eliminated altogether. Specifically, the interference and facilitation effects were found to be in evidence at the earliest stages of lexical processing (i.e., in first fixations, first pass measures, and skipping measures), but not in those measures assumed to tap into later interpretive processes (i.e., regression path duration and total reading times) when the critical words were embedded in high semantic constraint sentence contexts (e.g., Since they liked to gossip, they had an extended chat that lasted all night.). This suggests that even if bilingual lexical processing may be language nonselective, when the semantic context is constrained highly enough, any cross-language ambiguity can be resolved during later stages of the comprehension process. Such findings challenge theories of bilingual lexical processing, such as the bilingual interactive model (BIA+; Dijkstra \& Van Heuven, 2002), which, although designed to account for findings regarding bilinguals' processing of individual words, assumes an extremely limited role for language context in lexical processing in sentence contexts because there are no top-down language nodes that affect lexical activation in the model.

Support for the BIA+ model can be found, however, in another eyetracking study. Van Assche, Drieghe, Duyck, Welvaert, and Hartsuiker (2010) found cognate facilitation effects in both early and late fixation measures, unlike in the Libben and Titone (2009) study. They also found 
that the effect was graded such that facilitation increased with greater orthographic overlap between the cognates of the two languages. It is important to note that it may be proficiency that underlies the difference between the two studies. Specifically, the participants in the Van Assche et al. study were much less proficient than those in the Libben and Titone study, who, due to the fact that they lived in the bilingual context of Montreal, were more balanced bilinguals than the Dutch L2 learners of English in Belgium. It is therefore possible that cross-language activation effects are more strongly present in learners with less L2 proficiency or experience. Despite the differences in the results of these studies, it is clear that a more fine-grained picture of bilingual lexical processing can be obtained using eye-tracking as compared to other methods and that the results can better inform theories about the nature of the bilingual mental lexicon.

\section{Grammatical and Discourse Processing}

Processing Ambiguities: Investigating Parsing Strategies. Eye-tracking during reading has been used to good effect in the study of L2 learners' parsing (i.e., grammatical processing) procedures. For example, FrenckMestre and Pynte (1997) examined the eye movements of English-French bilinguals as they read structurally ambiguous sentences. In Experiment 1, the bilinguals read sentences in their L2 (i.e., French), and their performance was compared to native French speakers. The items were similarly ambiguous in the learners' L1 (i.e., English) and L2, as illustrated in (1). In this example, the critical prepositional phrase (PP) attaches to either the preceding verb (i.e., VP-attachment), as in (1a), or the noun (i.e., NP-attachment), as in (1b).

(1) a. VP-attachment:

Il accuse son chef de meurtre mais il ne peut pas fournir de preuve.

"He accuses his boss of murder but he cannot provide proof."

b. NP-attachment:

Il accuse son chef de service mais il ne peut pas fournir de preuve.

"He accuses his head of department but he cannot provide proof."

Given that earlier research with monolinguals had observed that VP-attachment was preferred over NP-attachment in globally ambiguous PP-attachment constructions (e.g., Brutus hit the gladiator with the shield), in line with phrase-structure-driven parsers such as the garden path model (Rayner, Carlson, \& Frazier, 1983), Frenck-Mestre and Pynte (1997) investigated whether L2 learners would also show such a preference. This would be evidenced by a processing difficulty with NP-attachment 
constructions (as in [1b]) in comparison to VP-attachment (as in [1a]). In contrast to phrase-structure-driven parsing models, which assume that the VP-attachment preference should be driven by the fact that it is structurally simpler than NP-attachment-irrespective of lexical information - the predictions of lexically based parsers (Boland, 1993) are that the lexical properties of the input, and of the main verb in particular, should influence initial parsing decisions. To test the predictions of the two types of parsing models, the authors created parallel stimulus sentences with monotransitive verbs as shown in (2). In these conditions, if the parser is guided by the lexical information in the initial verb, NPattachment, as shown in (2b), is predicted to be preferred over VPattachment, as shown in (2a), because only one argument is allowed. This contrasts with (1), in which, with the optionally ditransitive verbs, readers may be predicted to prefer VP-attachment for the first PP because they expect two arguments on the basis of the subcategorization information in the verb.

(2) a. VP-attachment:

Il connaît la femme de vue mais ne se rappelle plus son nom.

"He knows the woman by sight but no longer remembers her name."

b. NP-attachment:

Il connaît la femme de chambre mais ne se rappelle plus son nom.

"He knows the chambermaid but no longer remembers her name."

The subcategorization properties of the verbs were found to significantly affect both the native speakers' and the L2 learners' gaze durations on the critical region (i.e., the noun in the PP: vue vs. chambre). Specifically, longer reading times were induced for NP-attachments, as in (1b), versus VP-attachments in the ditransitive verb condition, as in (1a), and for VP-attachments, as in (2a), rather than NP-attachments, as in (2b), following monotransitive verbs. This was the case even though the noun in (2a) is shorter in length than that in (2b) and should thus elicit shorter reading times (i.e., vue vs. chambre). Given that the effects were observed in measures that are assumed to tap into earliest parsing decisions (and not in later measures), the authors argue that the data support a lexically driven over a phrase-structure-driven parser because subcategorization information was put to use immediately. Furthermore, L2 learners' parsing decisions were also affected by such lexical information in the early parsing stages, and their parsing procedures thus appeared to be qualitatively highly similar to those of native speakers (at least in their use of lexical-semantic information during real-time comprehension).

An effect of early parsing decisions was also found in the second experiment, in which Frenck-Mestre and Pynte (1997) addressed the question of whether the learners' L1 would influence their processing of syntactic 
ambiguities in their L2. Two groups of French-English bilinguals took part: those whose L1 was French and those whose L1 was English. The learners read experimental sentences in both French and English (which were blocked, in the same experiment, so that the participants could see no more than one version of each experimental item). In one condition, the experimental items comprised verbs, which were optionally transitive in English (e.g., obey) but obligatorily intransitive in French (e.g., obéir), as shown in (3a). Thus, only in English was the sentence temporarily ambiguous. This is a classic garden path construction in which it only becomes clear that the NP (e.g., the pretty little girl) is, in fact, not the object of the verb obey when the reader encounters the main verb showed. In the second condition, the verbs used were obligatorily intransitive and therefore unambiguous in both languages (e.g., bark and aboyer), as shown in (3b).

(3) a. Ambiguous in English-unambiguous in French:

Chaque fois que le chien obéissait la jolie petite fille montrait sa joie.

"Every time the dog obeyed the pretty little girl showed her approval."

b. Unambiguous in English and French

Chaque fois que le chien aboyait la jolie petite fille montrait sa joie.

"Every time the dog barked the pretty little girl showed her approval."

Again, the L2 learners' processing of the experimental items did not differ overall from that of native speakers. The authors broke down the critical sentences into different regions: the subordinate verb (e.g., obeyedobéissait), the ambiguous NP (la jolie petite fille-the pretty little girl), and the disambiguating main verb (montrait-showed). When reading the English sentences, more first pass regressions from the disambiguating main verb as well as second pass reading times were observed for the garden path sentences, as in (3a), than for the unambiguous items, as in (3b). This demonstrates both an early and a later effect of the syntactic ambiguity in both learner groups and suggests that all the learners had initially incorrectly analyzed the ambiguous NP (e.g., the pretty little girl) as the direct object of the subordinate verb (e.g., obeyed). Despite the evidence of this initial misanalysis for the garden path conditions overall, there was a fleeting effect of subcategorization differences; that is, both the French and the English learners' first pass reading times were longer on the English subordinate verbs, which differed in subcategorization properties between their L1 and their L2 (e.g., obey vs. obéir). Taken together, the results suggest that, like native speakers, L2 learners incrementally process the input-they attempt to integrate each word into their current analysis or representation of the sentence so far-and their initial parsing decisions are influenced by lexical information. However, where there are L1-L2 differences in such lexical-semantic information, this may momentarily affect their online processing. 
Detecting Ungrammaticalities in the Input. As well as being a highly useful tool to investigate parsing procedures, eye-tracking can also be used to ascertain L2 learners' grammatical knowledge and, critically, whether learners can access and make use of their knowledge during the real-time processing of the input. Data from such research can inform one of the major debates in L2 acquisition: whether or not (or to what extent) it is possible to acquire nativelike grammatical knowledge if the L2 is learned after puberty (see Lenneberg, 1967) and if the phenomenon is not instantiated in the learner's L1 (see Slabakova, 2009, for discussion). One way to examine the use of grammatical knowledge online is to assess participants' sensitivity to ungrammatical input during comprehension; eye-tracking during reading has been successfully used to this end. For example, Keating (2009) tested adult L1 English-L2 Spanish learners, with differing proficiency levels, on their acquisition and processing of abstract gender, following earlier research with conflicting findings as to whether learners of a language without abstract gender can successfully acquire gender agreement (Franceschina, 2001; Sabourin, Stowe, \& de Haan, 2006; White, Valenzuela, Kozlowska-Macgregor, \& Leung, 2004). The participants read grammatical and ungrammatical sentences in Spanish in which nouns were modified by postnominal adjectives to examine their ability to detect gender agreement violations. The critical constructions differed in distance between the NP and the modifying adjective, as illustrated in (4a)-(4c), to test the effects of having to compute the intervening material while holding the relevant noun in working memory until the dependency was established, which is thought to put the processing system under pressure (Gibson, Pearlmutter, Canseco-Gonzalez, \& Hickok, 1996).

(4) a. In the NP:

[IP Una casa pequeña [VP cuesta mucho en San Francisco.] ]

"A small house costs a lot in San Francisco."

b. In the matrix clause VP:

[IP La casa [VP es bastante pequeña y necesita muchas reparaciones.]]

"The house is quite small and needs a lot of repairs."

c. In the subordinate clause VP:

[IP Una casa [VP cuesta menos [CP si [VP es pequeña y necesita reparaciones]]]].

"A house costs less if it is small and needs repairs."

In the eye-tracking data, both longer fixation times on the critical adjective (e.g., pequeña "small") and the proportion of regressions from the adjective back to the noun to be modified when there was a mismatch in gender between the two (e.g., un libr-o [masc]. . . pequeñ- $a$ [fem] "a small $_{\mathrm{FEM}}$ book $_{\mathrm{MASC}}$ ") were assumed to indicate processing difficulty. In other words, this would reflect an online sensitivity to gender agreement 
errors and would thus be evidence of the ability to compute gender agreement in real-time comprehension. ${ }^{4}$

The participants' regressions were broken down into first pass regressions (i.e., the probability of regression from the critical adjective leftward to reread earlier parts of the text) and delayed regressions (i.e., the probability of regressive eye movements back to the critical adjective following a first pass through the critical region once the eyes had exited to the right). The learners' results showed effects of proficiency and of the distance between the head noun and the adjective. Specifically, only the highly advanced learners' reading profiles matched those of the native speakers and only in the condition in which the noun and the adjective were adjacent, like in (4a). In this local condition, the ungrammatical items elicited longer total reading times as well as more frequent total regressions (i.e., first pass and delayed regressions combined). This fixation pattern was also observed in the native speakers' data in the other two distance conditions. Thus, the author argued that the results, overall, suggest that it is possible for learners from an ungendered L1 to acquire gender agreement (see the full transfer-full access hypothesis, Schwartz \& Sprouse, 1996) in contrast to findings of offline studies (Franceschina, 2001; White et al., 2004), and in contrast to the predictions of the failed functional features hypothesis (Hawkins \& Chan, 1997). However, it appears that computing gender agreement becomes more difficult for L2 learners the more distant the adjective is from the head noun (see also Myles, 1995), even for those learners with very high proficiency, as in the Keating (2009) study. This is argued to support the hypothesis that L2 learners have trouble computing syntactic dependencies across multiple, but not local, clauses because of a lack of processing resources (see the shallow structure hypothesis [SSH], Clahsen \& Felser, 2006).

Another interesting finding in the Keating (2009) study is the lack of effects in the early fixation measures, even for native speakers. This differs from the results of a recent experiment with English L2 learners of French (Foucart \& Frenck-Mestre, 2012) that examined eye-fixation patterns on similar sentences with and without gender violations and in which the head noun and adjective were separated by a copular verb, as in (5).

(5) Au printemps les pommes [FEM] sont vertes [FEM] (*verts [MASC]) sur cet arbre. "In spring apples are green on this tree."

The authors found that ungrammatical items elicited longer first pass reading times as well as longer total reading times for both the native French speakers and the L2 learners. This suggests that the anomaly can be detected during the earliest stages of comprehension. However, it is possible that the difference in task may underlie the different findings between the two studies. In the Keating (2009) study, the participants performed a meaning-related task in which they assessed whether an 
English translation matched the meaning of the experimental sentence, whereas in the Foucart and Frenck-Mestre (2012) study, participants' attention might have been more explicitly drawn to the violation because they were required to judge the grammaticality of the sentences. A recent review of the L2 sentence-processing literature suggests that learners may be less likely to shallowly process the input under the task conditions of forced grammaticality judgment (Roberts, 2012a).

Processing Referential Dependencies. The results of the Keating (2009) and the Foucart and Frenck-Mestre (2012) studies focused on L2 learners' ability to apply their morphosyntactic knowledge during realtime processing. The eye-tracking technique has also been useful in the investigation of questions relating to L2 learners' application of syntactic constraints during parsing. Similar to the debate surrounding the question of whether or not (postpuberty) L2 learners have nativelike access to grammatical knowledge that is unavailable via their L1, one major debate in L2 sentence processing research involves the question of whether L2 learners' grammatical processing is qualitatively (see the SSH; Clahsen \& Felser, 2006) or quantitatively different from that of native speakers (see Hopp, 2006). Employing the eye-tracking technique can inform this debate. For instance, Felser, Sato, and Bertenshaw (2009) and Felser and Cunnings (2012) investigated the processing of reflexive pronouns by advanced Japanese and German learners of English. English native speakers have been found to immediately link a reflexive anaphor with only a grammatically appropriate-bindingaccessible-NP in earlier discourse (Nicol \& Swinney, 1989), in line with a syntactic constraint such as Principle A of Binding Theory (Chomsky, 1981). The authors were interested to see whether or not L2 learners would also apply such a constraint during real-time processing. Among the experimental items were short texts, as in (6), with a lead-in sentence in which two referents (e.g., John and Richard) were introduced into the discourse and were then both reintroduced. One of the referents-the local one-was binding accessible (e.g., Richard), and the other was binding inaccessible-that is, nonlocal but prominent in the discourse (e.g., John or Jane). The critical pronoun either agreed (e.g., John) or did not agree (e.g., Jane) in gender with either the accessible or inaccessible referents.

(6) John (Jane) and Richard were very worried in the kitchen of the expensive restaurant.

John noticed that Richard had cut himself (herself) with a very sharp knife.

The region of interest comprised the reflexive pronoun (e.g., himself) and a few following words to check for spillover effects. The native speakers' parsing indeed showed evidence of considering only the 
grammatically appropriate-and not the discourse-prominentantecedent as a referent for the pronoun; that is, they were slower to read those items in which there was a mismatch between the gender of the pronoun (e.g., herself) and the local, binding-accessible antecedent (e.g., Richard). This effect was evident in early measures (i.e., first pass reading times) as well as later measures (i.e., rereading times). The learners' later reading times patterned with the native speakers in these conditions, their rereading of the critical region and in all reading time measures in the postcritical region being evident.

Despite this, the L2 learners' fixation patterns differed from those of the native speakers in that there was a gender mismatch effect observed during their initial reading of the critical region (i.e., the reflexive pronoun) for conditions in which the discourse-prominent, binding-inaccessible referent differed in gender from the reflexive pronoun (e.g., Jane . . . Richard ... himself). This was found in both first fixation and first pass reading times. Thus, in these conditions, the learners appeared to consider-albeit fleetingly - the structurally inaccessible referent (e.g., Jane) as a potential antecedent, and this interfered with their earliest processing of the reflexive pronoun. This initial interference effect did not, however, affect their final interpretation of the reflexive pronouns, which was evidenced by the results of an offline grammaticality judgment task that showed a nativelike knowledge of these anaphors. Furthermore, because both the German and the Japanese learners performed similarly, even though German-like English (and unlike Japanese)-does not permit long-distance binding, the results are argued to support the SSH (Clahsen \& Felser, 2006). This hypothesis would predict that L2 learners' earliest analyses (here reflected in first pass reading times) are constrained by top-down, discourse-level locality conditions, rather than by bottom-up, structurally defined locality conditions, as observed for native speakers.

The finding that L2 learners' online interpretation of pronouns may be troubled by having a matching competitor antecedent in the preceding discourse without affecting final interpretations was also observed in an eye-tracking study on subject pronoun resolution with German and Turkish L2 learners of Dutch (Roberts, Gullberg, \& Indefrey, 2008). Both L2 groups patterned together and differently from Dutch native speakers. Specifically, their second pass and total reading times ${ }^{5}$ showed that when reading the critical region (i.e., the verb and subject: eet hij "he eats"), they were slower in the condition in which there were two grammatically matching referents available (Peter and Hans . . Peter . . . he), in comparison to the condition with only one grammatically available referent (The workers ... Peter ... he), as shown in (7).

(7) Peter en Hans (De werknemers) zitten in het kantoor. Terwijl Peter is aan het werken, eet hij een sandwich. 
"Peter and Hans (The workers) are in the office. While Peter is working, he is eating a sandwich."

The authors argued that during real-time comprehension, L2 learners find the integration of information from multiple sources (e.g., grammar or discourse-pragmatics) more problematic than do native speakers. The results also support the current idea in the L2 acquisition literature that such difficulty is caused by processing phenomena that lie at the (external) interfaces (e.g., between discourse-pragmatics and syntax; see the interface hypothesis, Sorace, 2011; Tsimpli \& Sorace, 2006) and that, therefore, this problem may be best attributed to processing rather than competence factors.

\section{CONCLUSION}

The eye-tracking technique has only recently begun to be employed in L2 research, yet it has been found to be highly useful in the investigation of important topics and addresses key debates in the fields of both lexical and sentence processing. As outlined in this article, the technique can be used to chart learners' processing procedures during the uninterrupted presentation of the input and is thus a more natural measure of processing than other online techniques. It can be applied to the study of the processing of ungrammatical versus grammatical input, and it (a) addresses questions about the nature of L2 knowledge and (b) examines learners' processing procedures, which include the handling of ambiguous input and the application of grammatical constraints online. Finally, given that the technique allows for a breakdown of natural reading into earlier and later processing stages, it is sensitive enough to pick up fleeting effects that may not be detected with other techniques and therefore offers a more complete picture of L2 learners' knowledge and the application of this knowledge during real-time comprehension.

\section{NOTES}

1. When discussing research on the mental lexicon, we follow the majority of researchers in the field of lexical processing, who use the term bilingual to refer to a L2 speaker of any proficiency level.

2. Regression path duration is sometimes considered a first pass measure (e.g., Sturt, 2003) or an early measure (e.g., Clifton, Staub, \& Rayner, 2007); in the present review, we treat it as a late measure because it reflects the cost of overcoming a processing difficulty, which is more typical of late processing stages (e.g., Clifton et al., 2007).

3. IP = inflectional phrase; $\mathrm{CP}=$ complementizer phrase.

4. One can conceive of this as a process of feature checking.

5. One may argue that total reading times offer us a measure similar to a button-push during SPR. However, although it is assumed that total reading times reflect a stage in comprehension in which full interpretative processing has taken place, as with a button-push 
in SPR, it might be that the latter task would not have been sensitive enough to pick up the effects, given the simplicity of the experimental texts.

\section{REFERENCES}

Altarriba, J., Kroll, J., Scholl, A., \& Rayner, K. (1996). The influence of lexical and conceptual constraints on reading mixed language sentences: Evidence from eye fixation and naming times. Memory and Cognition, 24, 477-492.

Altmann, G. (2011). Language can mediate eye movement control within 100 milliseconds, regardless of whether there is anything to move the eyes to. Acta Psychologica, 137, 190-200.

Balota, D., Pollatsek, A., \& Rayner, K. (1985). The interaction of contextual constraints and parafoveal visual information in reading. Cognitive Psychology, 17, 364-390.

Boland, J. E. (1993). The role of verb argument structure in sentence processing: Distinguishing between syntactic and semantic effects. Journal of Psycholinguistic Research, 2, 133-152.

Brysbaert, M., Drieghe, D., \& Vitu, F. (2005). Word skipping: Implications for theories of eye movement control in reading. In G. Underwood (Ed.), Cognitive processes in eye guidance (pp. 53-77). Oxford: Oxford University Press.

Brysbaert, M., \& Vitu, E. (1998). Word skipping: Implications for theories of eye movement control in reading. In G. Underwood (Ed.), Eye guidance in reading and scene perception (pp. 125-148). Oxford: Elsevier.

Camblin, C. C., Gordon, P. C., \& Swaab, T. Y. (2007). The interplay of discourse congruence and lexical association during sentence processing: Evidence from ERPs and eye tracking. Journal of Memory and Language, 56, 103-128.

Carpenter, P., \& Just, M. (1983). What your eyes do while your mind is reading. In $\mathrm{K}$. Rayner (Ed.), Eye movements in reading: Perceptual and language processes (pp. 275-307). San Diego, CA: Academic Press.

Chomsky, N. (1981). Lectures in government and binding. Dordrecht: Foris.

Clahsen, H., \& Felser, C. (2006). Grammatical processing in language learners. Applied Psycholinguistics, 27, 3-42.

Clifton, C., Jr., Staub, A., \& Rayner, K. (2007). Eye movements in reading words and sentences. In R. Van Gompel, M. Fisher, W. Murray, \& R. L. Hill (Eds.), Eye movement research: $A$ window on mind and brain (pp. 341-372). Oxford: Elsevier.

Costa, A., Caramazza, A., \& Sebastián-Gallés, N. (2000). The cognate facilitation effect: Implications for models of lexical access. Journal of Experimental Psychology: Learning, Memory, and Cognition, 26, 1283-1296.

De Groot, A. M. B. (2011). Language and cognition in bilinguals and multilinguals: An introduction. New York: Psychology Press.

Dijkstra, T., Grainger, J., \& Van Heuven, W. J. B. (1999). Recognition of cognates and interlingual homographs: The neglected role of phonology. Journal of Memory and Language, 41, 496-518.

Dijkstra, T., \& Van Heuven, W. J. B. (2002). The architecture of the bilingual word recognition system: From identification to decision. Bilingualism: Language and Cognition, 5, 175-197.

Duffy, A. A., Kambe, G., \& Rayner, K. (2001). The effect of prior disambiguating context on the comprehension of ambiguous words: Evidence from eye movements. In D. S. Gorfein (Ed.), On the consequences of meaning selection: Perspectives on resolving lexical ambiguity-Decade of behavior (pp. 105-117). Washington, DC: American Psychological Society.

Duyck, W., Van Assche, E., Drighe, D., \& Hartsuiker, R. (2007). Visual word recognition by bilinguals in a sentence context: Evidence for nonselective lexical access. Journal of Experimental Psychology: Learning, Memory, and Cognition, 33, 663-679.

Ehrlich, S. F., \& Rayner, K. (1981). Contextual effects on word recognition and eye movements during reading. Journal of Verbal Learning and Verbal Behavior, 20, 641-655.

Ellert, M. (2011). Ambiguous pronoun resolution in L1 and L2 Dutch(Unpublished doctoral dissertation). Radboud University Nijmegen, The Netherlands.

Ellert, M., Järvikivi, J., \& Roberts, L. (in press). Resolving ambiguous pronouns in a second language: A visual-world eye-tracking study in L2 German and Dutch. International Review of Applied Linguistics. 
Felser, C., \& Cunnings, I. (2012). Processing reflexives in English as a second language: The role of structural and discourse-level constraints. Applied Psycholinguistics, 33, 571-603.

Felser, C., Sato, M., \& Bertenshaw, N. (2009). The on-line application of binding Principle A in English as a second language. Bilingualism: Language and Cognition, 12, 485-502.

Fodor, J. D. (2002). Prosodic disambiguation in silent reading. In M. Hirotani (Ed.), Proceedings of the North East Linguistics Society: Vol. 1. (pp. 113-132). Amherst, MA: Graduate Linguistic Student Association.

Foucart, A., \& Frenck-Mestre, C. (2012). Can late L2 learners acquire grammatical features? Evidence from ERPs and eye-tracking. Journal of Memory and Language, 66, 226-248.

Franceschina, F. (2001). Morphological or syntactic deficits in near-native speakers? An assessment of some current proposals. Second Language Research, 17, 213-247.

Frenck-Mestre, C. (2005). Eye-movement recording as a tool for studying syntactic processing in a second language: A review of methodologies and experimental findings. Second Language Research, 21, 175-198.

Frenck-Mestre, C., \& Pynte, J. (1997). Syntactic ambiguity resolution while reading in second and native languages. Quarterly Journal of Experimental Psychology, Section A: Human Experimental Psychology, 50A, 119-148.

Gibson, E., Pearlmutter, N., Canseco-Gonzalez, E., \& Hickok, G. (1996). Recency preference in the human sentence processing mechanism. Cognition, 59, 21-39.

Hawkins, R., \& Chan, C. Y. (1997). The partial accessibility of Universal Grammar in second language acquisition: The failed functional features hypothesis. Second Language Research, 13, 187-226.

Henderson, J., \& Ferreira, E. (1990). Effects of foveal processing difficulty on the perceptual span in reading: Implications for attention and eye movement control. Journal of Experimental Psychology: Learning, Memory, and Cognition, 16, 417-429.

Hopp, H. (2006). Syntactic features and reanalysis in near-native processing. Second Language Research, 22, 369-397.

Hyönä, J. (1993). Effects of thematic and lexical priming on readers' eye movements. Scandinavian Journal of Psychology, 34, 293-304.

Indefrey, P. (2006). A meta-analysis of hemodynamic studies on first and second language processing: Which suggested differences can we trust and what do they mean? Language Learning, 56, 279-304.

Inhoff, A. W. (1989). Parafoveal processing of words and saccade computation during eye fixations in reading. Journal of Experimental Psychology: Human Perception and Performance, $15,544-555$.

Inhoff, A. W., \& Rayner, K. (1986). Parafoveal word processing during eye fixations in reading: Effects of word frequency. Perception and Psychophysics, 40, 431-439.

Just, M., \& Carpenter, P. (1980). A theory of reading: From eye fixations to comprehension. Psychological Review, 87, 329-354.

Keating, G. D. (2009). Sensitivity to violations in gender agreement in native and nonnative Spanish: An eye-movement investigation. Language Learning, 59, 503-535.

Kennison, S. M., \& Clifton, C., Jr. (1995). Determinants of parafoveal preview benefit in high and low working memory capacity readers: Implications for eye movement control. Journal of Experimental Psychology: Learning, Memory, and Cognition, 21, 68-81.

Lemhöfer, K., \& Dijkstra, T. (2004). Recognizing cognates and interlexical homographs: Effects of code similarity in language specific and generalized lexical decision. Memory and Cognition, 32, 533-550.

Lemhöfer, K., Dijkstra, T., \& Michel, M. C. (2004). Three languages, one ECHO: Cognate effects in trilingual word recognition. Language and Cognitive Processes, 19, 585-611.

Lenneberg, E. (1967). Biological foundations of language. New York: Wiley.

Libben, M., \& Titone, D. (2009). Bilingual lexical access in context: Evidence from eye movement recordings during reading. Journal of Experimental Psychology: Learning, Memory, and Cognition, 35, 381-390.

Liversedge, S., Paterson, K., \& Pickering, M. (1998). Eye movements and measures of reading time. In G. Underwood (Ed.), Eye guidance in reading and scene perception (pp. 55-75). Oxford: Elsevier.

Marian, V., \& Spivey, M. (2003). Competing activation in bilingual language processing: Withinand between-language competition. Bilingualism: Language and Cognition, 6, 97-115. 
McConkie, G., \& Rayner, K. (1975). The span of the effective stimulus during a fixation in reading. Perception and Psychophysics, 17, 578-586.

McDonald, S., \& Shillcock, R. (2003). Eye movements reveal the on-line computation of lexical probabilities during reading. Psychological Science, 14, 648-652.

Myles, F. (1995). Interaction between linguistic theory and language processing in SLA. Second Language Research, 11, 235-266.

Nicol, J., \& Swinney, D. (1989). The role of structure in co-reference assignment during sentence comprehension. Journal of Psycholinguistic Research, 18, 5-20.

Paterson, K., Liversedge, S., \& Underwood, G. (1999). The influence of focus operators on syntactic processing of short relative clause sentences. The Quarterly Journal of Experimental Psychology, 52, 717-737.

Pollatsek, A., Rayner, K., \& Balota, D. A. (1986). Inferences about eye movement control from the perceptual span in reading. Perception and Psychophysics, 40, 123-130.

Rayner, K. (1975). Parafoveal identification during a fixation in reading. Acta Psychologica, $39,271-282$.

Rayner, K. (1998). Eye movements in reading and information processing: 20 years of research. Psychological Bulletin, 124, 372-422.

Rayner, K. (2009). The 35th Sir Frederick Bartlett Lecture: Eye movements and attention during reading, scene perception, and visual search. Quarterly Journal of Experimental Psychology, 62, 1457-1506.

Rayner, K., \& Bertera, J. H. (1979). Reading without a fovea. Science, 206, 468-469.

Rayner, K., Carlson, M., \& Frazier, L., (1983). The interaction of syntax and semantics during sentence processing. Journal of Verbal Learning and Verbal Behavior, 22, 358-374.

Rayner, K., \& Duffy, S. (1986). Lexical complexity and fixation times in reading: Effects of word frequency, verb complexity, and lexical ambiguity. Memory and Cognition, 14, $191-201$.

Rayner, K., \& Pollatsek, A. (1989). The psychology of reading. Englewood Cliffs, NJ: Prentice Hall.

Rayner, K., Sereno, S., Morris, R., Schmauder, A., \& Clifton, C. (1989). Eye movements and on-line language comprehension processes. Language and Cognition Processes, 4, 21-49.

Rayner, K., Warren, T., Juhasz, B. J., \& Liversedge, S. P. (2004). The effects of plausibility on eye movements in reading. Journal of Experimental Psychology: Learning, Memory, and Cognition, 30, 1290-1301.

Rayner, K., \& Well, A. (1996). Effects of contextual constraint on eye movements in reading: A further examination. Psychonomic Bulletin and Review, 3, 504-509.

Rayner, K., Well, A., \& Pollatsek, A. (1980). Asymmetry of the effective visual field in reading. Perception and Psychophysics, 27, 537-544.

Roberts, L. (2012a). Individual differences in second language sentence processing. In L. Roberts \& A. Meyer (Eds.), Individual differences in second language learning. Oxford: Blackwell.

Roberts, L. (2012b). Psycholinguistic techniques and resources in second language acquisition research. Second Language Research, 28, 113-127.

Roberts, L., Gullberg, M., \& Indefrey, P. (2008). Online pronoun resolution in L2 discourse: L1 influence and general learner effects. Studies in Second Language Acquisition, 30, 333-357.

Sabourin, L., Stowe, L. A., \& de Haan, G. J. (2006). Transfer effects in learning a second language grammatical gender system. Second Language Research, 22, 1-29.

Schwartz, A. I., Kroll, J. F., \& Diaz, M. (2007). Reading words in Spanish and English: Mapping orthography to phonology in two languages. Language and Cognitive Processes, 22, 106-129.

Schwartz, B., \& Sprouse, R. A. (1996). L2 cognitive states and the Full Transfer/Full Access model. Second Language Research, 12, 40-72.

Siyanova-Chanturia, A., Conklin, K., \& Schmitt, N. (2011). Adding more fuel to the fire: An eye-tracking study of idiom processing by native and nonnative speakers. Second Language Research, 27, 251-272.

Siyanova-Chanturia, A., Conklin, K., \& van Heuven, W. (2011). Seeing a phrase "time and again" matters: The role of phrasal frequency in the processing of multi-word sequences. Journal of Experimental Psychology: Language, Memory, and Cognition, 37, 776-784. 
Slabakova, R. (2009). L2 fundamentals. Studies in Second Language Acquisition, 31, 155-173.

Sorace, A. (2011). Pinning down the concept of "interface" in bilingualism. Linguistic Approaches to Bilingualism, 1, 1-33.

Sturt, P. (2003). The time-course of the application of binding constraints in reference resolution. Journal of Memory and Language, 48, 542-562.

Tsimpli, I.-M., \& Sorace, A. (2006). Differentiating interfaces: L2 performance in syntaxsemantics and syntax-discourse phenomena. In D. Bamman, T. Magnitskaia, \& C. Zaller (Eds.), Proceedings of the 30th annual Boston University Conference on Language Development, BUCLD 30 (pp. 653-664). Somerville, MA: Cascadilla Press.

Van Assche, E., Drieghe, D., Duyck, W., Welvaert, M., \& Hartsuiker, R. J. (2010). The influence of semantic constraints on bilingual word recognition during sentence reading. Journal of Memory and Language, 64, 88-107.

Van Assche, E., Duyck, W., Hartsuiker, R. J., \& Diependaele, K. (2009). Does bilingualism change native-language reading? Cognate effects in a sentence context. Psychological Science, 20, 923-927.

Van Gompel, R. P. G., \& Pickering, M. J. (2001). Lexical guidance in sentence processing: A note on Adams, Clifton, \& Mitchell (1998). Psychonomic Bulletin and Review, 8, 851-857.

Van Hell, J. G., \& De Groot, A. M. B. (2008). Sentence context affects lexical decision and word translation. Acta Psychologica, 128, 431-451.

Van Hell, J. G., \& Dijkstra, T. (2002). Foreign language knowledge can influence native language performance in exclusively native contexts. Psychonomic Bulletin and Review, 9, 780-789.

Vasishth, S., \& Drenhaus, H. (2011). Locality in German. Dialogue and Discourse, 1, 59-82.

Vitu, F., McConkie, G. W., \& Zola, D. (1998). About regressive saccades in reading and their relation to word identification. In G. Underwood (Ed.), Eye guidance in reading and scene perception (pp. 101-124). Oxford: Elsevier.

White, S. (2008). Eye movement control during reading: Effects of word frequency and orthographic familiarity. Journal of Experimental Psychology: Human Perception and Performance, 34, 205-223.

White, L., Valenzuela, E., Kozlowska-Macgregor, M., \& Leung, Y.-K. I. (2004). Gender and number agreement in nonnative Spanish. Applied Psycholinguistics, 25, 105-133.

Wilson, F. (2009). Processing at the syntax-discourse interface in second language acquisition (Unpublished doctoral dissertation). University of Edinburgh, UK. 